\title{
Cognitive models of social integration processes
}

\author{
Mikhail Rozin ${ }^{1}$, Valery Svechkarev ${ }^{1}$, Zhanna Tumakova ${ }^{1}$, Olga Popkova ${ }^{1, *}$ \\ ${ }^{1}$ Southern Federal University, 105/42, Bolshaya Sadovaya str., Rostov-on-Don, Russia
}

\begin{abstract}
This article provides an overview of the rationale behind the social integration processes research. It identifies analytical advantages of the cognitive modelling that are based on the conceptual connections existing in the model architecture and convey dynamics of its operation through their causality. This article demonstrates that the cognitive model of the vertical and horizontal social integration ensures consistent social solidarity, however, it does not allow to accelerate the pace of the social integration processes and thus maintains societal anomie in the process of social reproduction. We propose the cognitive model of sustainable development of social reproduction based on empathy and social cohesion accelerators. Integration procedures in this model result from structural organization of the relationship between the primary social reproduction circuit and auxiliary circuits as well as from activating the mechanisms of dynamic interference between the named circuits. Each auxiliary circuit with positive feedback (growth cycle) is fitted with the social cohesion accelerator (growth factor) that ensures targeted amplification of the empathic potential in a given cycle, while all cycles together contribute to a continued long-term effect of the empathic potential amplification required for stable social reproduction in society.
\end{abstract}

\section{Introduction}

The topicality of the current research into the social integration processes is explained by increasing interest in social self-organization and self-determination [1] and is built upon the results achieved in economic integration analysis [2,3].

It is known that integration processes initiate both structural changes, such as augmentation and diversification of internal connections, and dynamic harmonization, such as development of modes of interaction between its stakeholders [4]. Enhancement of the social integration is accompanied by significant progress in various social spheres that eventually contributes to the main goal of integration, that is social reproduction in society. Alternatively, a slowdown in the social integration processes leads to difficulty in attaining the said goal [5]. Given that social reproduction determines social evolution and maintains multidimensionality and systemic stability of society, we claim the importance of the research into the integration processes. In its turn, integration processes are assumed to be actively and coherently happening together with the processes of social consolidation and

${ }^{*}$ Corresponding author: doptaganka@yandex.ru 
solidarity. Our approach provides essential possibility for simultaneous study of the specified processes aimed at social reproduction. However, to pursue this study it is necessary to improve "the conceptual, methodological and analytical tools used to research the issues of social consolidation, social integration, social solidarity, and cohesion" and abandon the "highly heuristic paradigm"[6].

\section{Research Methodology}

Let us consider the possibilities to research the integration processes in society with the use of cognitive modelling methodology. Cognitive modelling has already proved to be effective for the analysis of various aspects of the social issues (for example, refer to [1,7]). From analytic point of view using cognitive modelling is beneficial in that it makes essentially possible graphic representation of the structural-functional description of the social integration processes. In this case conceptual connections of the cognitive model displays structure of the processes, while their causality represents dynamics of these processes. It is worth noting that academic-economists similarly ascertained the necessity to account for the dynamic effects of integration (for example, refer to [8]).

\section{Research Object}

As our research object we review a flow model designed with the use of "vertical and horizontal vectors of social integration" [6]. It displays two starting points for the implementation of consolidation process, i.e. the micro- and macrosocial solidarity. Thereby social solidarity is implemented along two basic vectors: vertical (macrosocial) where consolidation process or flow is vectored from power holders to society and back and horizontal (microsocial) where consolidation flow leads to social reproduction. Normally, two consolidation flows complement each other and lead to consistent solidarity which in its turn maintains balance in the social organization by stabilizing it and enforcing its viability. Weakening of any of these flows will inevitably result in some kind of social imbalance when real consolidation mechanisms do not function any longer, but social unity may still remain intact for some time by virtue of social inertia. For further analysis we constructed a cognitive model that represents the above described process through vertical (macrosocial) and horizontal (microsocial) vectors of social consolidation (refer to Figure $1)$.

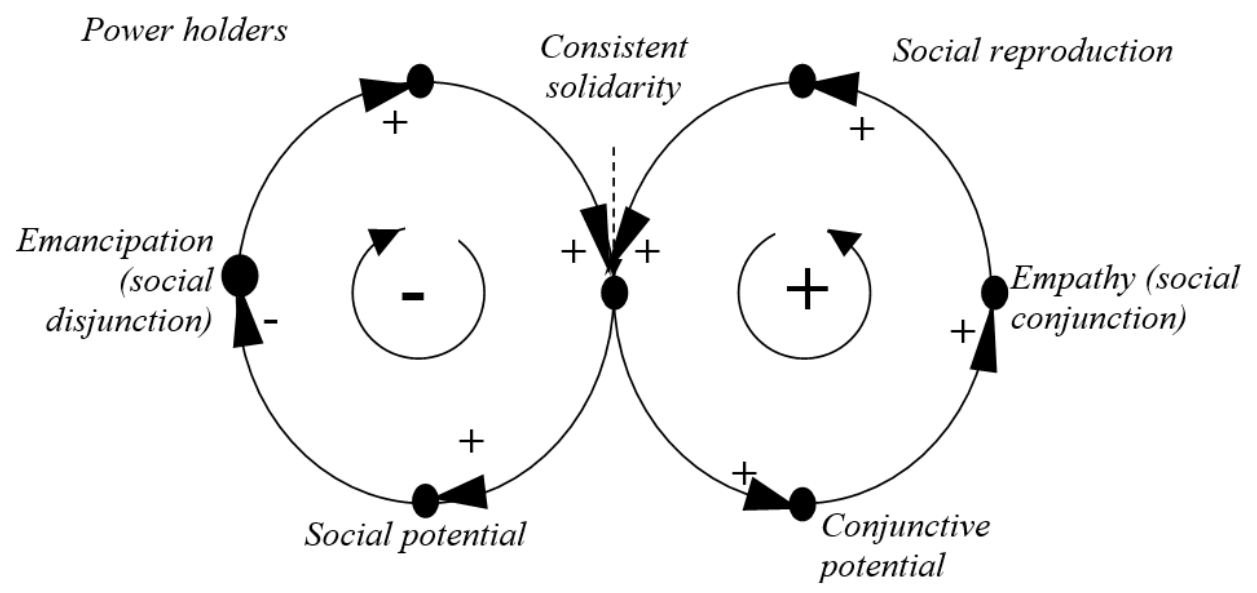

Fig. 1. Cognitive model of vertical and horizontal social consolidation processes according to $[5,6]$. 
This is a double-circuit model comprised of macro- and microsocial circuits. Two circuits are integrated into a single system where consistent solidarity emerges at the point of their intersection. Consistent solidarity in the macrosocial circuit causes changes in the level of social potential, that is a growth of consistent solidarity triggers a growth of social potential, while a decline of solidarity correspondingly results in a decline of social potential (causality sign - plus). Power holders in this circuit are separated and emancipated from society through the social disjunction procedure. It is emancipation that is responsible for negative feedback in macrosocial circuit (causality sign - minus) and thus restores balance of the relationship between social potential and powder holders and radically eliminates the possibility of critical prevalence of either of them. A growth of either of these factors will inevitably result in its stabilization as a response to changes in the circuit.

In contrast, consistent solidarity in the microsocial circuit gives rise to the conjunctive potential that further allows to trigger conjunctive process $[5,6]$ embodied in conjunctive practices of various types (unions, relations, associations, etc.). What is essentially indicative of the true potential of social conjunction is empathy. High level of empathy is something what creates sympathetic, understanding, and cooperative attitudes in society exceptionally important for the establishment of social reproduction and enhancement of consistent solidarity. This is how the circuit with positive feedback is formed that continuously triggers changes in the level of consistent solidarity.

Integration of circuits with positive and negative feedback in the model of vertical and horizontal social consolidation allows to avoid shift of society towards the state of imbalance when real conjunctive practices in the microsocial circuit are no longer functional and thus endanger the process of social reproduction. If this happens, regulative feedback of the macrosocial circuit comes into action to maintain the current level of consistent solidarity.

\section{Analysis of integration processes}

In summary, despite significant advantage of the cognitive model of vertical and horizontal social consolidation processes (refer to $[5,6]$ ), namely its stabilizing effect on consistent solidarity in society, it does not allow to augment (amplify) integration processes and, hence, maintains societal anomie in the process of social reproduction. Anomie results in disfunction of the above described circuits of the model with the macrosocial (vertical) circuit ceasing to operate in the first place as stated in [5]. That is why it is so important to identify causes of anomie in the macrosocial circuit, analyze the possibilities for transition toward sustainable development of social reproduction in society and form the mechanisms for its implementation immediately in the microsocial circuit.

As it is stated in [9], "anomie in our society emerged due to abrupt abandonment of the previously sanctioned collective values and norms and complete corruption of the mechanism for social construction of" reality. In fact, society merely forfeited the "sanctioned" collective norms engendered by power holders in the macrosocial circuit and enforced through consistent solidarity in the microsocial circuit as real conjunctive practices of "social construction". In response to a decline in the process of the collective norm generation in the macrosocial circuit, auxiliary circuits may be formed which would allow for consistent development of social reproduction in the microsocial circuit.

It is obvious that the auxiliary circuits are generated with an aim to increase the empathic potential level as a fundamental factor of social reproduction. Herewith a growth of empathy should make it possible to launch social construction of the natural collective social norms particularly at the microlevel. Below we review the proposed cognitive model of sustainable development of social reproduction in society (ref. to Fig. 2). 


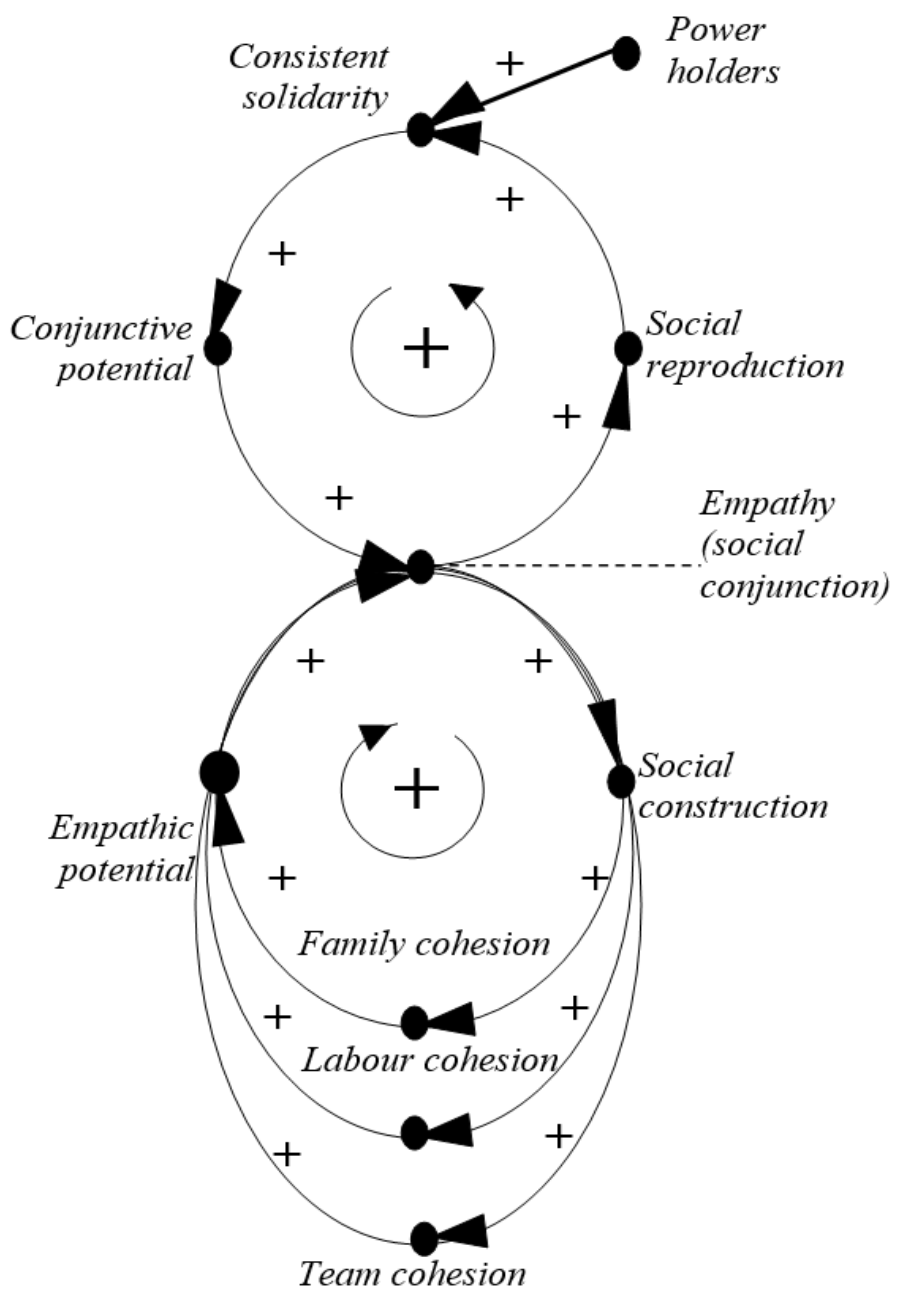

Fig. 2. Cognitive model of sustinable development of social reproduction in society based on the mechanisms of empathy and social cohesion accelerators.

The microsocial circuit is a primary circuit of the present cognitive model with consistent solidarity, conjunctive potential and empathy (social conjunction) included into the social reproduction cycle. Similar to the previously reviewed model (ref. to Fig. 1) consistent solidarity retains its core position and additionally integrates potential collective norms engendered by power holders into the social repdocution cycle. However, it is empathy that already causes initial integration. As we have mentioned before, the microsocial circuit employs positive feedback that causes further changes in the same direction. To achieve a relevant growth of social reproduction, it is required to ensure an uninterrupted "primary" growth of social conjuction that will be sustained in the positive feedback circuit. Therefore, the integration procedures caused by empathy both result from he structured interconnection of the primary circuit with the auxiliary one and trigger the mechanisms of dynamic interaction between the said circuits.

We suggest using a model with several positive feedback loops in the capacity of the auxiliary circuits connected to the primary circuit at the empathy junction point. Such multiloop models became a frequent practice in economic, technological, and social systems where it is necessary to achieve a growth in company's profit or production 
volume or amplify targeted social determination [7,10]. An accelerator (growth factor) is built into each cycle (growth cycle) with positive feedback which ensures purposeful amplification in the given cycle, while all cycles together will produce an uninterrupted, long-term growth, amplification, development effect [10].

Each auxiliary circuit (empathy amplification cycles) of the proposed model includes empathic potential, empathy (social conjunction), and social construction causes as well as one of the accelerators that triggers a corresponding integration mechanism. Corresponding norms of development and are decomposed into the cycles with a specific cohesion accelerator at the social construction point. Collective empathy potencies generated in each circuit are integrated at the empathic potential point. In the cognitive model shown in Figure 2 sustainable social reproduction is achieved by integrating cohesion accelerators into the empathy amplification cycles that activate family, labour and team cohesion mechanisms.

It is obvious that the number of collective integrators is not limited to the abovementioned accelerators and they may tap from the resources of other social communities (from family and socio-occupational group to territorial and ethnocultural communities), systems of social organization (political, economic, legal, etc.) and symbolic systems (moral code, ideology, and everyday discourse) [5,6]. It is crucial that the process of social construction is based on the norms of social cohesion that forms a social integration accelerator within the framework of social conjunction and eliminates the possibility of social disjunction (emancipation, separatism, etc.). Another critical point is to achieve dynamics of the developmental cycle. It is necessary to aim towards balanced employment of the highly dynamic cycles (for example, generated in economic systems) and the cycles with a long-lasting response to the growth impulses (for example, those associated with changes in ethnocultural communities). In this case a long-term sustainable maintenance of the level of empathic potential becomes achievable. However, depending on the current social situation a resonance overlapping of cycles with the similar temporal responses is possible. In this case, it is worth counting on the development of the high-level empathic potential that is required, as an example, to kick start a targeted procedure of social conjunction.

Anyhow, the defined structure of the auxiliary circuits integrated with the cohesion accelerators connects to the microsocial circuit at the empathy point. Thereby an uninterrupted transmission of the empathic potential into the social reproduction cycle is ensured. Positive feedback in the circle stimulates self-change of the consistent solidarity, conjunctive potential, and empathy (social conjunction) causes toward amplification of social reproduction. In this way organization of integration processes in line with the given model allows to make a fundamental shift from the state of stagnation in social reproduction towards social development.

\section{Conclusion}

1. In this article we have identified analytical advantages of the cognitive modelling for the research of social integration processes that are based on the conceptual connections existing in the model architecture and convey dynamics of its operation through their causality.

2. We have demonstrated that despite significant advantage of the cognitive model of vertical and horizontal social consolidation processes, namely its stabilizing effect on consistent solidarity in society, nevertheless it does not allow to augment (amplify) integration processes and, hence, maintains societal anomie in the process of social reproduction. 
3. We have proposed the cognitive model of sustainable development of social reproduction based on empathy and social cohesion accelerators. Integration procedures in this model result from structural organization of the relationship between the primary social reproduction circuit and auxiliary circuits as well as from activating the mechanisms of dynamic interference between the named circuits. Each auxiliary circuit with positive feedback (growth cycle) is fitted with the social cohesion accelerator (growth factor) that ensures targeted amplification of the empathic potential in a given cycle, while all cycles together contribute to a continued long-term effect of the empathic potential amplification required for stable social reproduction in society.

\section{Acknowledgements}

This article was funded by the internal project grant of the Southern Federal University No. ВнГр-07/2020-05-ФП.

\section{References}

1. M.D. Rozin, V.P. Svechkarev, Zh.A. Tumakova, SHS Web Conferences, International scientific conference: Achievements and perspectives of philosophical studies (APPSCONF-2019) (2019) doi: https://doi.org/10.1051/shsconf/20197204005

2. O.Yu. Michurina, E.P. Karlina, Ekonomika. Vestn. INZhEKONA 2(37), 118-124 (2010)

3. D.I. Ushkalova, Vestnik Instituta Ekonomiki Rossiiskoj Akademii Nauk 2, 187-199 (2016)

4. M. Rubin, Journal of Diversity in Higher Education 5, 22-38 (2012)

5. O.A. Karmadonov, Sotsiologicheskie Issledovaniya 2, 3-12 (2015)

6. O.A. Karmadonov, G.D. Kovrigina, Vestnik Instituta Sotsiologii 2(17), 12-28 (2016)

7. L.V. Tarasenko, M.D. Rozin, V.P. Svechkarev, Media Education (Mediaobrazovanie) 59(4), 588-593 (2019)

8. B. Balassa, Journal of Common Market Studies 14(1), 37-55 (1975)

9. V.G. Fedotova, Sh. Kross, Obshhestvennye nauki i sovremennost' 2, 41-51 (2006)

10. Z. Achi, Eh. Domehn, O. Siboni, D. Sinkha, S. Vitt, The McKinsey Quarterly 3, 4-17 (1995) 